\title{
El ejemplar perdido del Arte de putear de Moratín (c. 1815-1820): nuevos datos ecdóticos y bibliográficos
}

\author{
Álvaro PIQUERO RODRIGUEZ \\ Universidad Complutense de Madrid
}

\begin{abstract}
RESUMEN
La donación a la Biblioteca Nacional de España de un ejemplar perdido del Arte de putear de Nicolás Fernández de Moratín (1737-1780) ha abierto nuevas e interesantes perspectivas de estudio para la crítica. El presente trabajo pretende, por un lado, recuperar la historia que se escondía detrás de esta editio princeps, publicada clandestinamente a principios del siglo XIX; y por otro, exponer los problemas críticos — adiciones, supresiones, contaminaciones y sustituciones - que muestra el poema a la luz de su cotejo con los restantes testimonios conservados.
\end{abstract}

Palabras clave: Erotismo, poesía, Moratín, censura, ecdótica.

\begin{abstract}
The donation of a lost copy of the Arte de putear of Nicolás Fernández de Moratín (17371780) to the National Library of Spain has brought to light new and interesting perspectives of study for the critics. On one hand, this article pretends to recover the history hidden behind this first edition, published underground at the beginning of the Century $19^{\text {th }}$. On other hand, it presents the critical problems, such as additions, eliminations, contaminations and replacements, that the poem shows according to his comparison with the remaining testimonies conserved.
\end{abstract}

Key words: Eroticism, poetry, Moratín, censorship, first edition. 
El Arte de putear, de Nicolás Fernández de Moratín, es un texto eróticoburlesco, disfrazado bajo la máscara de tratado didáctico-moral, que, en cuatro largos cantos, nos describe un interesante y explícito recorrido prostibulario por las calles de Madrid, con una mención detallada de las trabajadoras, su localización, sus tarifas y sus costumbres. Como cabía esperar, este espinoso tema pronto despertó los recelos de la Inquisición, que, en un edicto de 1777, prohibió la lectura y la distribución del poema, condenándolo definitivamente a una existencia clandestina. La obra moratiniana, pues, se transmitió a través de manuscritos y ediciones piratas, hecho éste del que se derivan una serie de problemas editoriales que hoy continúan siendo motivo de discusión crítica.

Hasta la fecha, los testimonios del texto que se habían podido manejar eran únicamente tres; sin embargo, a veces el caprichoso azar se pone de nuestra parte: en los primeros compases del año 2012, doña Mercedes Dexeus Mallol donó a la Biblioteca Nacional de España un ejemplar perdido del Arte de putear.

El trabajo que aquí presentamos se propone desentrañar cada uno de los detalles bibliográficos de este recuperado ejemplar, el único conservado de la tirada que se hizo del poema a principios del siglo XIX, y que, como se verá, pasa por ser la primera edición conocida de la obra. Además, en aras de presentar un estudio completo de la situación crítica actual, a lo largo de este trabajo adoptaremos dos perspectivas distintas, pero definitivamente complementarias: por un lado, el estudio exhaustivo de la historia de la obra, y de este ejemplar en particular, para poner de manifiesto las razones por las cuales el libro ha permanecido oculto hasta la actualidad; y por otro, la collatio con los otros testimonios conocidos y el análisis de las variantes. Todo ello con la intención de dilucidar la necesidad o no de una nueva edición crítica del poema en cuestión.

\section{Los problemas de transmisión del Arte de putear}

La primera noticia que conservamos del Arte de putear nos la brinda la Inquisición, que en el Edicto manuscrito de la Ynquisición de Corte del 20 de junio de 1777, firmado por Felipe Mego, señala:

19. Vn Papel, o Poema manuscrito en 106 páginas en quarto, intitulado $=$ Arte de las Putas, que tiene a continuación de este título varios versos de Ovidio en su obra de Arte amandi; y está dividido en quatro Cantos, de los que el primero empieza =Hermosa Venus, que al amor presides; y concluye el quarto y vltimo = el dulce Moratín fue mi maestro. Se prohíbe enteramente, aun para los que tengan licencia de leer libros prohibidos, por estar lleno de proposiciones falsas, 
escandalosas, provocativas a cosas torpes, injuriosas a todos los estados del Christianismo, blasfemas, heréticas, y con sabor de Ateísmo, y Politeísmoํ.

Además de lo anterior, esta prohibición, como era costumbre en la época, debió de ser colgada en las puertas de las iglesias con el fin de que todo el pueblo pudiera conocer la peligrosidad del pernicioso poema, como demuestra este Vejamen satírico compuesto por Iriarte en 1779:
y por maestro de un Arte
muy semejante al de Ovidio, ha visto inmortalizados
sus versos y su apellido
en las puertas de los templos, no menos que en un Edicto ${ }^{2}$.

Más allá de estas tres fechas, pocas han sido las referencias cronológicas concretas que la crítica ha podido recuperar para datar el poema. Así pues, la primera dificultad que nos encontramos a la hora de acercarnos críticamente al Arte de putear es la cronología de la obra, pues la crítica especializada ha venido manejando fechas bastante dispares, desde 1769 hasta 1777. Empezando por la última, algunos estudiosos, como Emilio Palacios Fernández, han supuesto que el poema debió de escribirse hacia $1777^{3}$. Don Antonio Rodríguez-Moñino, más precavido, únicamente lo juzga «escrito antes de 1777», ya que parece evidente que el poema tuvo que redactarse antes de la prohibición inquisitorial ${ }^{4}$. Realmente, la posibilidad de que la obra fuera compuesta el mismo año en el que aparece el Edicto es muy reducida, pues hay que tener en cuenta que el Santo Oficio prohibía un poema cuando circulaba ya en suficientes versiones manuscritas como para ser conocido por un público más o menos amplio.

Tampoco debemos aceptar, no obstante, la tesis del insigne profesor don Marcelino Menéndez Pelayo, que prefiere retrasar la fecha de composición del poema hasta los años de juventud del autor: «algún tributo pagó en sus mocedades a la poesía licenciosa [...] No en sus obras impresas, sino en cierto poema inédito,

\footnotetext{
${ }^{1}$ Inquisición (1777), fols. [3v-4v]. La misma información, aunque más reducida, la encontramos en el Índice de 1790: «Arte de las putas. Poema manuscrito en 106 págg. [sic], así intit. Se divide en 4. Cantos: el I. empieza: Hermosa Venus, que el amor presides: y el 4. Acaba: El dulce Moratín fue mi maestro. Edicto de Junio de 1777», Inquisición (1790), p. 16 .

2 Apud E. Cotarelo y Mori (2006), pp. 511-512. Para que no queden dudas, en la nota al pie [n. 18] se aclara que «Moratín compuso un poema intitulado: Arte de las p., que se ha prohibido».

${ }^{3}$ E. Palacios Fenández (1980), p. 22.

${ }^{4}$ A. Rodríguez Moñino (1955), p. 123, n. 59.
} 
cuyo título no puede estamparse aquí $[\ldots]\rangle^{5}$. En efecto, esta hipótesis no puede sostenerse por las propias pruebas textuales que aporta la obra, pues en aquellos versos (III, 245-255) en los que se citan los mejores lugares para encontrar mujeres del oficio, se nombran los bailes de máscaras que el conde de Aranda organizó desde 1767 hasta 1773 en el teatro de los Caños del Peral ${ }^{6}$.

Dejando de lado estas dos fechas, que adelantan o retrasan demasiado la aparición del texto, hemos de reconocer que la mayor parte de los estudios críticos abogan por una composición cercana al año 1772: ya sea entre 1771 y $1772^{7}$ o en $1772^{8}$. La primera mención al año 1772 la encontramos en la «Advertencia» preliminar del anónimo editor del poema en 1898, mucho más cercano a la composición del texto que ninguno de los posteriores:

[...] un bibliófilo muy inteligente nos manifestó tener un vago recuerdo de haber visto otro manuscrito fecha [sic] en 1772 y no hay, a nuestro juicio, motivo para rechazar esta fecha como aproximada?

Esta fecha se correspondería con los años en los que el ilustre poeta dedicaba su tiempo a las letras y a los amigos en la tertulia de la Fonda de San Sebastián, cuya etapa de esplendor coincidiría con la década que va desde 1770 a 1780 . De hecho, dado que los temas tratados en la tertulia se alejaban en numerosas ocasiones de los considerados sanos y ortodoxos, no sería descabellado pensar que fue entre estas cuatro paredes donde Nicolás Fernández de Moratín escribió el lúbrico poema. Así lo defienden la mayor parte de los críticos que se han acercado a él, aunque en ningún caso se ha podido aportar prueba documental alguna ${ }^{10}$.

Teniendo en cuenta la cantidad y la calidad de las investigaciones citadas, parece claro que la composición del poema debió de desarrollarse muy posiblemente en una fecha indeterminada entre 1767 y 1772 . No obstante, la fecha de creación más verosímil estaría en torno a esos dos primeros años de la década de los setenta, pues la Fonda de San Sebastián aún no había comenzado sus festivas tertulias en los últimos años de la anterior.

\footnotetext{
${ }^{5}$ M. Menéndez Pelayo (1963), pp. 303-304.

${ }^{6}$ Véase Advertencia (1898), p. 8. Información ampliada por M. Fernández Nieto (1977), p. 164, n. 247.

${ }^{7}$ D. Thatcher Gies (1979), pp. 14, 36, 100 y (1980), p. 320.

${ }^{8}$ Advertencia (1898), p. 8, con quien coinciden M. Fernández Nieto (1977), pp. 41-42; I. Colón y G. Garrote (1995), 16 o E. Palacios Fernández (2006), p. 212. P. Deacon (2004), p. 834 , abre más el abanico y aboga por fecharlo hacia 1770-1775; de forma similar procede V. Orazi (2012), p. 3, que lo supone escrito entre 1767 y 1777.

${ }^{9}$ Advertencia (1898), p. 8.

${ }^{10}$ Véase, entre otros, M. Fernández Nieto (1977), p. 42 y (1980), p. 49; D. Thatcher Gies (1979), p. 36; I. Colón y G. Garrote (1995), p. 14; o E. Palacios Fernández (2006), p. 212.
} 
Si no hay unanimidad en relación con la fecha de composición del poema, tampoco la vamos a encontrar a la hora de titularlo, como ocurre habitualmente al abordar el estudio de este tipo de obras clandestinas. El lector avezado ya habrá notado que existen dos títulos en conflicto: Arte de las putas, título que utiliza el Edicto citado algunas páginas atrás y que adoptan la mayor parte de sus editores, y Arte de putear, denominación que hemos venido utilizando a lo largo de este estudio basándonos en otra rama de la tradición textual.

La mayor parte de la crítica, basándose en el testimonio del Edicto y en de la edición de 1898, que se creía la primera publicación del texto, se decantan por el primero de los títulos apuntados en el párrafo anterior: Arte de las putas ${ }^{11}$. En relación con este tema, es muy sugerente el análisis semántico que desarrolla Pedro Ruiz Pérez, quien defiende la naturaleza polisémica del título a través de una serie de observaciones que, aunque muy lúcidas, no parecen del todo convincentes ${ }^{12}$.

Aquí, sin embargo, basándonos en varios testimonios de la obra y en los estudios y opiniones de Philip Deacon e Isabel Colón y Gaspar Garrote ${ }^{13}$, hemos optado por utilizar el segundo de los títulos apuntado anteriormente: Arte de putear. En efecto, el título por el que nos decantamos en este estudio, Arte de putear, es, por un lado, el que aparece en la copia manuscrita más antigua conservada, y por otro, el que su editor elige la primera vez que el texto fue llevado a la estampa: Álbum de Venus, seguido del Arte de putear de Moratín.

Además, dejando a un lado las cuestiones más estrictamente editoriales, la propia exégesis del poema invita a defender esa última titulación: «como la fuente principal del poema es el Arte de amar de Ovidio [...], su título debería incluir mejor un infinitivo que un sustantivo [...]. Asimismo, el poema no versa tanto de putas como de la relación con mujeres prostituidas $[\ldots]\rangle^{14}$. Estamos, pues, ante un poema que intenta instruir a sus lectores en los mejores modos y maneras para disfrutar de los servicios meretricios, pero en el que nada o casi nada se dice acerca de las rijosas «artes» que las mujeres del oficio debían desplegar a la hora de saciar el voraz apetito de sus clientes.

Una última cuestión que debemos tener en cuenta a la hora de enfrentarnos a la obra es aquella que está relacionada con los problemas de transmisión, pues de nuevo las opiniones de los críticos navegan en direcciones opuestas. Una buena parte de los estudiosos defienden un conocimiento limitado del texto por parte de sus contemporáneos, tanto por el círculo cerrado en el que surgió como por la posterior prohibición inquisitorial que, en un principio, limitaría de tal manera la recepción del texto que terminaría abocando al poema a un largo silencio, ya que no

\footnotetext{
${ }^{11}$ Así lo denomina, entre otros, M. Fernández Nieto (1977), E. Helman (1970), D. Thatcher Gies (1979), E. Palacios (1980) o V. Orazi (2012).

12 P. Ruiz Pérez (1996), pp. 175-185.

${ }^{13}$ P. Deacon (1980), p. 114, n. 39; I. Colón y G. Garrote (1995), p. 20.

${ }^{14}$ I. Colón y G. Garrote (1995), p. 20.
} 
volvería a ser mencionado más allá del Índice de $1790^{15}$. Otros estudiosos de la materia, empero, abogan por una difusión del texto más amplia de la que podríamos pensar en un primer momento, ya que los manuscritos pirata debieron de multiplicarse antes de la prohibición inquisitorial, llegando incluso a los primeros años del siglo XIX. A este respecto, son muy reveladores los comentarios de Víctor Infantes:

[...] hasta su inclusión definitiva en el Índice [...], se multiplicaron las copias manuscritas. Hay constancia de más de una docena de papeles, algunos sólo fragmentarios, que contienen los versos $[\ldots]^{16}$.

No siendo el objetivo de este trabajo confirmar ni desmentir ninguna de las dos hipótesis anteriores, únicamente dedicaremos las siguientes líneas a describir los manuscritos y ediciones de los que tenemos constancia física en la actualidad. Además, con el fin de que el análisis sea lo más exhaustivo posible, más allá de los datos materiales, hemos decidido incluir una amplia nota complementaria final en las fichas bibliográficas que aportan información nueva para la crítica, con lo que conseguiremos redondear completamente la información aportada en la descripción.

\section{Manuscritos y ediciones impresas}

Perdido el original del poema, y probablemente también aquél que manejó la Inquisición, ya fuera o no el autógrafo, sólo se conservan tres copias manuscritas de la obra ${ }^{17}$ :

\section{1. $\mathrm{F}^{18}$}

Arte de [putear] de Moratin; 7 de octubre de 1804; 260x150 mms.; 2 hs. de guarda modernas +1 h. de guarda +2 hs. +88 págs. +2 hs. de guarda modernas.

\footnotetext{
15 Así opinan M. Fernández Nieto (1977), p. 18 y P. Ruiz Pérez (1996), pp. 176-177.

${ }^{16}$ V. Infantes (1998), pp. VI-VII. En este sentido, conviene tener en cuenta los datos aportados por M. Défourneaux (1973), I. Zavala (1983) y P. Deacon (2004) y (2006) en sus estudios sobre la transmisión del libro erótico en España.

${ }^{17}$ El propio profesor Infantes, en conversaciones privadas, me confirma que ha tenido entre sus manos al menos otra copia manuscrita más que habría que añadir a las ya conocidas, aunque lamentablemente no hemos tenido la oportunidad de consultarla personalmente para la confección de este trabajo.

${ }^{18}$ Denominación fijada por I. Colón y G. Garrote (1995), p 17, basándose en el apellido del copista: Laurent Falcon. Para una amplia y detallada descripción del manuscrito véase I. Colón y G. Garrote (1995), pp. 110-118. Debo mostrar mi agradecimiento tanto a la Biblioteca de la Real Academia Española como a sus bibliotecarios por su amabilidad a la hora de consultar físicamente el manuscrito y por la presteza con la que me enviaron una copia digitalizada.
} 
Encuadernación holandesa moderna, firmada por «B. Vera», burdeos, papel, caja de escritura 240x130 mms., lomo de piel con seis nervios, en el segundo internervio, en dorado: «MORATIN / ARTE DE PUTEAR / MANUSCRITO», y tejuelo de la biblioteca con la signatura en el sexto.

Madrid, Biblioteca de la Real Academia Española-Legado de don Antonio Rodríguez-Moñino y doña María Brey, M-RAE, RM-7184 (ex-Antonio RodríguezMoñino y doña María Brey).

D. Thatcher Gies (1980), p. 320, cita la fecha 1813 erróneamente; I. Colón y G. Garrote (1995), pp. 109-12, lo describen; V. Orazi (2012), pp. 24-25, lo describe y cita la fecha 24 de septiembre de 1804 erróneamente.

2. $* \mathrm{C}^{19}$

Arte de putear; 1822; 280x170 mms.; 76 págs.

Encuadernación moderna, tapa dura, papel, 23-26 líneas por página.

Cambridge, Cambridge University Library, Department of Manucripts and University Archives, Ms. Add. 7.813 (ex-Richard Heber, ex-Thomas Phillipps).

F. Aguilar Piñal y P. Deacon (1980), p. 277, nº 19, lo citan; I. Colón y G. Garrote (1995), p. 17], lo citan; V. Orazi (2012), p. 25, lo describe.

3. * $\mathrm{U}^{20}$

[Arte de las putas]; s. a.; 215x160 mms.; 1h. de guarda moderna +2 hs. +10 fols. $+1 \mathrm{~h}$. de guarda moderna.

19 Denominación fijada por V. Orazi (2012), p. 25, primera editora en cotejar este manuscrito. Ante la imposibilidad de consultar este testimonio físicamente, basamos la descripción del manuscrito en el amplio estudio de esta misma edición, V. Orazi (2012), pp. 25-31. Allí deberá acudir el lector interesado en los pormenores bibliográficos de este manuscrito.

${ }^{20}$ Denominación fijada aquí por primera vez, en base a la ciudad donde se conserva el documento. Debo mostrar mi agradecimiento a los bibliotecarios de la Bibliotheek der Rijksuniversiteit (Utrecht) por su amabilidad a la hora de resolver las cuestiones por las que les he interrogado y por la presteza con la que me enviaron una copia digitalizada del manuscrito. Ante la imposibilidad de consultar el manuscrito físicamente, baso esta descripción en su digitalización, de manera que el análisis carecerá inevitablemente de datos materiales exactos. 
Encuadernación moderna, papel, 17-24 líneas por página.

Utrecht, Utrecht University Library, Bibliotheek der Rijksuniversiteit, Collectie Spaans-Portuguees Instituut, Ms. 11, map. 11.2. (ex-Vicente Salvá, ex-Ricardo Heredia, ex-Raymond Foulché-Delbosc, ex-John L. Gili, ex-Spaans-Portuguees Instituut).

F. Aguilar Piñal y P. Deacon (1980), p. 275, n 7, lo citan; I. Colón y G. Garrote (1995), p. 17, lo citan; V. Orazi (2012), p. 25, lo cita.

Nota. Buen estado de conservación. En el ángulo superior izquierdo de la contratapa, a lápiz, se lee: «11)», en el lado opuesto, con tinta marrón: «Provenance: Vicente Salvá $n^{\circ} 136 »$ y debajo «Ricardo Heredia $n^{\circ} 1696 »$, con una línea que subraya ambas referencias. En la parte superior, con la misma tinta, leemos: «Perfecciones que debe tener una mujer [espacio en blanco] Trés léger ${ }^{21} »$, y debajo, a lápiz, en letra moderna: «mp.d. [?] Cuentos y Poesías más que...». Debajo de lo anterior, se lee: «Canto $1^{\circ}$ : Hermosa Venus... [espacio en blanco] Impublicable: grossier et sans valeur», debajo, de nuevo a lápiz, en letra moderna: «could be or seems to be by Moratin, $\alpha$ in his hand writing». Las observaciones a lápiz, bastante borrosas, muy probablemente pertenecen al bibliotecario que catalogó el manuscrito.

En la hojas [1r-2v], con tinta marrón, 16-17 líneas, se copia el poema anónimo «Perfecciones que deve tener una muger para ser notablemente hermosa», todo él escrito aparentemente por la misma mano.

De los folios 1r al 8v se copia, con tinta negra, un fragmento del Canto I del Arte de putear de Moratín [«Hermosa Venus» (fol. 1r)...«se alzó las respetables sopalandas» (fol. $8 \mathrm{v})$ ], quedando los dos últimos folios $(9 \mathrm{r}-10 \mathrm{v})$ en blanco ${ }^{22}$. El texto aparentemente fue copiado por una mano diferente a la del primer poema, pues, por ejemplo, tiene un trazo muy distinto en las $g$ y en las $s$, estas últimas cuando se encuentran en final de palabra. Asimismo, todo el poema parece haber sido reproducido por la misma mano, aunque a partir del folio $4 \mathrm{r}$ tiende a hacer el trazo más grande, de tal manera que el número de líneas por página va disminuyendo. Este cambio probablemente se deba al cansancio del copista, ya que los errores y correcciones también se multiplican en la segunda mitad del texto: mientras que hay tachones en los folios $5 \mathrm{v}, 6 \mathrm{r}, 7 \mathrm{r}$ y $7 \mathrm{v}$, hasta ese momento únicamente habíamos encontrado un error en 2 r. Por último, debemos apuntar que,

21 «Demasiado ligero».

${ }^{22}$ En el punto correspondiente de este trabajo veremos cómo la copia realmente no reproduce hasta el v. 555 del Canto I, pues una clara alteración del orden de los versos provoca que haya un importante salto desde el v. 216 al v. 446. 
a pesar de la nota del bibliotecario, difícilmente se puede atribuir la copia del poema al propio Moratín.

El manuscrito perteneció, en primera instancia, a la biblioteca de Vicente Salvá, como se apunta en la misma contratapa. En el Catálogo de la Biblioteca Salvá de 1872, se anota:

POESÍAS ERÓTICAS de varios autores de fines del siglo XVIII y principios del XIX. Manuscrito en $4^{\circ}$.

Comprende este legajo composiciones de diferentes poetas modernos: entre ellos descuellan D. Tomás de Iriarte, D. Juan Meléndez Valdés y D. Leandro Fernández de Moratín. La mayor parte son inéditos y difícilmente verán la luz pública por ser demasiado obscenos ${ }^{23}$.

También en la contratapa se indica su siguiente poseedor, Ricardo Heredia, Conde de Benahavis, que compró una parte de la Biblioteca Salvá tras la muerte del librero valenciano. En el Catalogue de la bibliothèque de M. Ricardo Heredia, Comte de Benahavis, de 1891, encontramos una referencia muy similar a la anterior:

Poésies espagnoles érotiques de divers auteurs de la fin du XVIII ${ }^{\mathrm{e}}$ siècle et du commencement du XIX ${ }^{e}$ siècle. In-4 de 86 ff. en feuvilles.

Recueil contenant dés poésies de D. Tomás de Iriarte, D. Juan Meléndez Valdés, D. Leandro Fernández de Moratín, etc., la plupart INÉDITES et fort libres.

Provient de la bibliothèque SALVÁ $\left(\mathrm{n}^{\circ} 316\right)^{24}$.

Tras estos dos primeros poseedores, el manuscrito pasó a engrosar la enorme colección de Raymond Foulché-Delbosc. Muerto el insigne hispanista, una buena parte de su fondo bibliográfico fue a parar a la librería Dolphin Book Co. Ltd., de Oxford, dirigida por John L. Gili. La pista de los manuscritos, pues, reaparece en el catálogo de manuscritos españoles publicado por dicha librería a principios de los años 60:

POESÍAS DEL SIGLO XVIII. A collection consisting of sixteen different sections of published and unpublished MSS of poetry, kept in a box in the shape of a book, with lock.

This was obiously one of Foulsché-Delbosc's favourite collection of manuscripts, to judge by the way in which they are kept and by the fact that some of the contents were published in the Revue Hispanique and elsewhere. They consist mostly of MSS. by Meléndez Valdés, Moratín, Iglesias, and principally Cadalso, as well as many anonymous pieces, such as the MS. which was partly reproduced in Cuentos y poesias más que picantes.

${ }^{23}$ V. Salvá (1872), p. 148, no 316.

${ }^{24}$ M. R. Heredia (1891), pp. 75-76, no 1696. 
The principal provenance of the MSS. is from Salvá and Heredia collection $[\ldots]^{25}$.

Muy probablemente fuera hacia 1963 cuando el Spaans-Portuguees Instituut comprara estos preciados manuscritos dieciochescos. Finalmente, tras la desaparición de la institución en 1974, su colección pasó a engrosar los fondos de la Utrecht University Library, donde descansa actualmente este fragmento del Arte de putear, que, teniendo en cuenta las antiguas descripciones, parece haber sido desgajado de la amplia colección anterior ${ }^{26}$.

En cuanto a las ediciones impresas, actualmente sólo se conservan dos anteriores al siglo $\mathrm{XX}^{27}$ :

\section{BNE}

Álbum de Venus, seguido del Arte de Putear de Moratín, s.1., s. i., s. a., $16^{\circ}$ apaisado, pp. 64-102. Es en esta edición en la que se centra nuestro trabajo, por lo que será objeto de amplio análisis en secciones posteriores.

\section{2. $* \mathrm{M}^{28}$}

Arte de las putas. Poema. Lo escribió Nicolás Fernández de Moratín. Ahora por primera vez impreso, Madrid, s. i., 1898, $8^{\circ}$ (130x180 mms.), 95 págs.

A. Palau y Dulcet (1951), p. 334, no 89.413, lo cita; A. Rodríguez-Moñino (1959), p. 123, n. 59, lo cita; F. Aguilar Piñal y P. Deacon (1980), p. 287, nº 83, lo citan; I. Colón y G. Garrote (1995), p. 18, lo describen; J. A. Cerezo (2001), pp. 108-109, n ${ }^{\circ} 147$, lo describe; J. L. Guereña (2011), pp. 67-70, n ${ }^{\circ} 21$, lo describe; V. Orazi (2012), p. 26, lo describe.

Existe una reedición facsímil: Arte de las putas debido al cálamo de Nicolás Fernández de Moratín entre los Árcades de Roma Flumisbo Thermodonciaco, A la luz de nuevo en su centenario con una Iniciatio ad usum lupanaris poeticae de Un Árcade futrosófico [Víctor Infantes] (1898-1998), Barcelona: Delstres, 1998.

${ }^{25}$ J. L. Gili (1963), p. 39, no 166.

${ }^{26}$ Debo estos últimos apuntes sobre la historia del manuscrito a la gentileza de Bart Haski, archivero de la Utrecht University Library.

27 Tras la transición democrática, el número de publicaciones se ha multiplicado notablemente tanto aquí como en el extranjero, llegando a superar la decena.

${ }^{28}$ Denominación fijada por I. Colón y G. Garrote (1995), p. 18, en base al a ciudad de publicación, Madrid. Para este trabajo nos hemos basado en la reedición facsímil de 1998. Téngase en cuenta, además, que J. L. Guereña (2011), p. 67, $\mathrm{n}^{\circ} 21$, recoge la cita de hasta siete ejemplares distintos de esta misma edición. 
Una vez descritos someramente todos los testimonios de los que se tiene constancia hasta el momento, debemos ya dejar de lado los problemas de transmisión general y centrarnos únicamente en una de sus ediciones: el ejemplar del Arte de putear reaparecido en el año 2012, pues siendo la primera impresión conocida (y no estudiada) del poema, estamos convencidos de que su análisis puede arrojar nueva luz sobre la historia textual de la obra de Moratín.

\section{El ejemplar perdido: Álbum de Venus, seguido del Arte de putear de Moratín}

Dada la importancia documental que tiene esta reaparecida edición del poema moratiniano, hemos creído oportuno desarrollar a lo largo de este punto un exhaustivo análisis bibliográfico del libro. Para ello, utilizaremos una ficha similar a las desarrolladas anteriormente en la descripción de manuscritos.

\section{$\mathrm{BNE}^{29}$}

Álbum de Venus, seguido del Arte de putear de Moratín; s. 1., s. i., s. a., pero ¿Madrid?, c. 1815-1820; $16^{\circ}$ apaisado (130x98 mms.); 2 hs. +64 págs. +102 págs. +4 hs.; errores numerosísimos y continuos en la paginación, por lo que realmente contiene 65 págs. +101 págs.

Encuadernación en piel marroquín, verde, tapas recuadradas por un filete fino, dorado, lomo con cinco nervios: en el segundo internervio, en dorado: «ALBUM DE VENUS», enmarcado arriba y abajo con dos filetes finos del mismo color que ocupan todo el lomo, en el sexto internervio tejuelo de la biblioteca con la signatura actual, los restantes internervios están decorados con adornos tipográficos dorados en forma de cruz.

Madrid, Biblioteca Nacional de España, Sala Cervantes, R/41561 (ex-Francisco Asenjo Barbieri, ex-Luis Carmena y Millán, ex-José Bilbao, ex-José Subirá, exJaime Moll Roqueta, ex-Mercedes Dexeus Mallol).

A. Palau y Dulcet (1951), p. 334, no 84.913, lo cita; A. Rodríguez-Moñino (1959), p. 123, n.59, lo cita y describe brevemente; M. Fernández Nieto (1977), p. 19, n. 5, lo cita; F. Aguilar Piñal y P. Deacon (1980), p. 285, nº 69, lo citan; I. Colón y G.

\footnotetext{
${ }^{29}$ Denominación fijada aquí por primera vez en base a la biblioteca donde se conserva actualmente el ejemplar. En este punto, debo agradecer a la Biblioteca Nacional de España y a sus bibliotecarios el haberme permitido examinar físicamente el ejemplar, de consulta restringida, todas las veces que ha sido necesario, así como la presteza con la que me han solucionado una gran parte de las dudas bibliográficas que me han asaltado durante esta investigación. Por último, téngase en cuenta que existe, por un lado, una versión digitalizada del texto disponible en línea, en la Biblioteca Digital Hispánica de la Biblioteca Nacional de España, (<http://bdh-rd.bne.es/viewer.vm?id=0000060908\&page=1> Última visita: 09/12/2015), y por otro, una edición moderna del ejemplar, A. Piquero (2014).
} 
Garrote (1995), p. 17, lo citan; J. L. Guereña (2011), pp. 56-57, n ${ }^{\circ} 11$, lo cita y describe brevemente.

Nota. Ejemplar en buen estado de conservación, aunque los bordes de las tapas se encuentran bastante desgastados y las dos primeras hojas del ejemplar están descosidas. Existen algunas hojas rasgadas (págs. 1, pegada con celo, 24 y 31 de la primera numeración o las págs. 21, 22, 23, 24, 73, 74 y 76 de la segunda) y algunas otras con manchas de humedad (págs. 1 y 41 de la primera numeración), aunque ninguno de estos desperfectos afecta a la lectura del texto. A lo largo de la edición parecen ir entremezclándose diferentes tipos de papel, de forma y calidad variables.

En la portada, impresa en papel rosa y aparentemente pegada a otro papel más resistente con el fin de evitar daños, se lee: ALBUM DE VENUS | seguido | DEL ARTE DE PUTEAR | de | MORATÍN», con un curioso detalle priápico en la primera preposición de. Debajo, una lámina muestra una pareja de amantes, desnudos, besándose delante de un fondo natural de ambiente clásico, todo ello bajo la atenta mirada de Cupido, que se encuentra al lado de los dos jóvenes.

En la hoja [1v], a lápiz, se anota la signatura de la biblioteca: «R/41561». En la hoja [2r], con bolígrafo azul, en letra moderna, se lee:

\section{3 de mayo de 1935}

Obsequio de D. José Bilbao

Este ejemplar había pertenecido a Barbieri, Carmena y Millán anteriormente. Lo tuvo después Rodríguez Moñino y me lo devolvió más tarde. Había otro ejemplar desaparecido en la Bibl. Nac.

En la esquina inferior derecha del recto de la última hoja de guarda, al revés y a lápiz, la misma mano anota: «23.5.1935 | Obsequio de D. José Bilbao | Obra rarísima». El autor de ambas anotaciones manuscritas, a juzgar por el cotejo con otros testimonios, debe ser don José Subirá, uno de los poseedores que más tiempo tuvo entre sus manos el ejemplar.

El Álbum de Venus, págs. 1-64 de la primera numeración, presenta errores continuos en la paginación, con repeticiones de algunos números y ausencia de otros, de tal forma que sólo son correctos los números del 1 al 7, del 13 al 17, del 19 al 21, del 29 al 30, el 33, del 35 al 37, del 39 al 41, del 43 al 51 y del 53 al 56. En cuanto a su contenido, el impreso incluye una antología poética de autor(es) anónimo(s) que reúne hasta dieciocho poemas de tipo erótico-pornográfico. La única composición que hemos podido reconocer es el soneto "A la vía láctea» (pág. 33), atribuido tradicionalmente a don José de Espronceda ${ }^{30}$. A lo largo de esta antología libidinosa se imprimen hasta diez láminas pornográficas (págs. 13, 17, 21,

\footnotetext{
${ }^{30}$ Aunque se sale de los límites de este trabajo, debemos apuntar aquí que, teniendo en cuenta las fechas en las que nos movemos con relación a este ejemplar, difícilmente se podrá seguir manteniendo esta atribución.
} 
$24,31,33,39,43,53$ y 56), en blanco y negro, en papel de diferentes texturas y colores: marrón, verde, rosa, amarillento y azul celeste. En ellas, encontramos escenas de todo tipo: parejas fornicando, masturbaciones, felaciones, e incluso una especie de santificación del coito que muestra el aparato genital masculino y femenino encuadrados bajo un aura divina (pág. 33).

El Arte de putear, págs. 1-102 de la segunda numeración, también presenta problemas en su paginación, pues al confundir el número 3 con el 4, el impreso termina por estampar el número 102 en la página 101. A lo largo del poema hay numerosas anotaciones manuscritas modernas, a lápiz, probablemente de la mano de don José Subirá, pues son similares a las que hemos transcrito anteriormente. Estos apuntes, prácticamente ilegibles, en algunas ocasiones suelen añadir versos o palabras que faltan (págs. 5, 6, 8, 15, 32 o 38, entre otras), mientras que, en otras, simplemente marcan algunos versos, ya sea con una línea vertical (págs. 7, 37, 14, $17,19,30,41,50,63$ o 64, entre otros) u ondulada (pág. 42), con una flecha (págs. 6 y 61), con una marca en forma de f minúscula (págs. 14, 15, 28, 44 o 45, entre otras) o, incluso, rodeando los términos (págs. 36, 38 o 39, entre otras). Estas anotaciones demuestran una lectura atenta del texto por parte de don José Subirá, quien debió manejar una versión diferente del poema con el fin de introducir algunos de los versos omitidos en esta edición. En concreto, el texto que utilizó el musicólogo a la hora de incluir las anotaciones fue el de M, como se deduce del hecho de que él mismo poseyera uno de los ejemplares de esta estampación ${ }^{31}$ y de las variantes textuales encontradas en la colación.

Capítulo aparte merecen en esta ocasión todos aquellos datos que hemos podido encontrar en relación con la posible fecha de impresión y con los diferentes poseedores que han guardado secretamente esta curiosa edición decimonónica durante casi doscientos años.

La primera de estas cuestiones es quizá la más espinosa, puesto que los impresores que se decidían a sacar a la luz de forma clandestina este tipo de obras, en la mayoría de las ocasiones, obviaban o falsificaban los datos de impresión requeridos legalmente con el fin de evitar cualquier tipo de sanción por parte de los organismos oficiales. Así pues, a priori, no poseemos ningún tipo de información tipográfica sobre el posible lugar y la fecha de impresión del ejemplar descrito arriba.

La única referencia que se ha podido manejar hasta el momento acerca del posible año de publicación del libro la brindó, en 1951, el librero Antonio Palau y Dulcet: «tampoco debe creerse lo de "primera vez impreso", puesto que nuestro amigo José Subirá posee ejemplar de una edición sin año (pero hacia 1830), $8^{\circ}$ apaisado, con grabados y láms. [...]» ${ }^{32}$. Fuera de esta breve observación del librero

${ }^{31}$ J. L. Guereña (2011), pp. 67-70, $\mathrm{n}^{\circ} 21$.

${ }^{32}$ A. Palau y Dulcet (1951), p. 334, no 89.413. 
catalán, nada más se ha podido argumentar en torno a la fecha de publicación del texto, pues la imposibilidad de su consulta física por parte de la crítica especializada ha supuesto un grave impedimento.

Actualmente, sin embargo, la posibilidad de analizar personalmente el papel con el que se imprimió esta peregrina edición del poema de Moratín ha permitido afinar un poco más esta referencia temporal. En efecto, al mirar a contraluz la parte inferior izquierda de una de las láminas que jalonan la primera parte del impreso, el Álbum de Venus (pág. 21), advertimos la existencia de un fragmento de filigrana, formada por tres letras mayúsculas: «GRI[...]». Pues bien, según hemos podido comprobar, esta filigrana podría corresponderse con la que utilizaba en algunos de sus impresos don Santiago Grimaud. Este empresario papelero, que había comenzado su andadura en el molino de Gárgoles de Abajo, en el municipio de Cifuentes (Guadalajara), decidió continuar su camino de forma independiente y, en 1800, fundó una fábrica de papel propia en la vecina localidad de Gárgoles de Arriba. En concreto, la filigrana que nos ocupa parece haber sido estampada en el papel utilizado para la impresión del tomo primero del Tratado de economía política, de J. B. Say, publicado en Madrid en 1821, y en ella se puede leer el

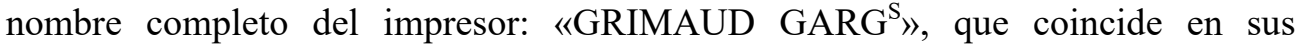
primeras letras con la marca encontrada en el impreso que venimos analizando ${ }^{33}$. Habida cuenta de la referencia anterior, y considerando que la capital era indudablemente uno de los puntos de venta principales de estos molinos de Guadalajara, parece muy razonable que el lugar de impresión del Álbum de Venus, seguido del Arte de putear de Moratín sea Madrid, en torno al año 1820.

Más allá de esta más o menos fiable referencia temporal, sí podemos aportar aquí un dato indubitable: la fecha de impresión del ejemplar del Arte de putear no puede ser en ningún caso posterior a 1847, pues don Santiago Grimaud únicamente permaneció en su fábrica hasta ese año, en el que la adquirió don Juan Manuel Barrio $^{34}$.

La última vía que hemos podido encontrar para datar la edición está relacionada con la vestimenta de los personajes que aparecen retratados en las láminas. Si bien este tipo de testimonios suelen ser menos fiables que los aportados en el párrafo anterior, hay que tener en cuenta que, tras el análisis sistemático de todas las ilustraciones, sí hemos conseguido llegar a una conclusión que permite afinar siquiera un paso más la datación del libro. Dentro de la escasez de ropa que presentan las láminas, la prenda que más llama la atención es el pantalón. Según hemos podido comprobar, a lo largo de todo el siglo XVIII y principios del XIX la moda del pantalón aún no se había impuesto en los principales centros europeos,

\footnotetext{
${ }^{33}$ Para consultar la filigrana y la historia completa de esta fábrica de papel véase G. Gayoso Carreira (1994), t. 1, pp. 80-8 y t. 3, p. 36, nº 54.

${ }^{34}$ G. Gayoso Carreira (1994), p. 83.
} 
por lo que en esta época los hombres vestían sus piernas con calzones y medias, siguiendo la moda aristocrática. Será principalmente en la década que va desde 1815 hasta 1825 cuando el pantalón comience a imponerse en la vestimenta masculina, tanto en Inglaterra como en Francia, ya que su uso llegó a considerarse como «una expresión de libertad y de democratización» ${ }^{35}$.

En definitiva, si a las pruebas documentales de los primeros párrafos le añadimos el hecho de que todos y cada uno de los hombres que aparecen vestidos en las láminas del Álbum de Venus cubren sus piernas con un pantalón, la conclusión más lógica a la que podemos llegar es que el impreso clandestino debió ver la luz entre los años 1815 y $1820^{36}$.

Una vez cerrada la primera de las dos cuestiones que nos habíamos propuesto dilucidar a lo largo de estos párrafos, debemos ahora centrarnos en todo aquello que tiene que ver propiamente con la historia del ejemplar, cuestión para la cual disponemos de muchos más datos que en el caso anterior.

Antes de su donación, únicamente teníamos unas pocas referencias de esta edición. Como ya apuntamos arriba, la primera reseña nos la brinda el librero catalán Antonio Palau, que cita el ejemplar e incluso se atreve a proponer una fecha de publicación aproximada. La siguiente referencia bibliográfica la aporta don Antonio Rodríguez-Moñino, que en 1959, tras haber tenido en sus manos el libro custodiado por don José Subirá, apunta: «[...] lo cierto es que hay por lo menos otra edición en las págs. 1-102 (segunda numeración) del Álbum de Venus, seguido del Arte de Putear de Moratín, peregrino volumen s. i. t., pero estampado hacia 1830 $\left(16^{\circ}, 64-102 \text { págs. y finas láminas) }\right\rangle^{37}$.

Por su parte, Manuel Fernández Nieto, primer editor moderno de la obra en 1977, comenta:

Por lo que se refiere a la existencia de otra edición, don José Subirá, amablemente, me comunica que, en efecto, hace muchísimo tiempo tuvo en sus manos un ejemplar de esta obra moratiniana [...], pero que ignora quién la posee en la actualidad $^{38}$.

\footnotetext{
${ }^{35}$ F. Boucher (1967), pp. 360-374.

${ }^{36}$ La posibilidad de que esta temprana edición del Arte de putear se publicara en Madrid y en torno a este lustro tampoco resulta nada descabellada si atendemos al mercado editorial erótico de la época, Guereña (2011), $\mathrm{n}^{\mathrm{os}}$ 6, 35, 37, 57, 62, 90, 111, 161 y 173.

${ }^{37}$ A. Rodríguez-Moñino (1959), p. 123, n. 59.

${ }^{38}$ M. Fernández Nieto (1977), pp. 17-18, n. 5. I. Colón y G. Garrote (1995), p. 17, los siguientes editores del poema, no aportan ninguna información nueva en relación con esta edición. V. Orazi (2012), pp. 23-31, por su parte, no menciona en su edición ningún dato relacionado con este ejemplar.
} 
Sólo tras la donación del libro a la Biblioteca Nacional hemos podido, al fin, conocer pormenorizadamente la historia de este raro ejemplar del poema, que había permanecido custodiado durante este largo tiempo en las bibliotecas de algunos de los más insignes bibliófilos de las últimas centurias. En efecto, como ya apuntamos en la descripción bibliográfica —hoja [2r] - don José Subirá anota de su propio puño todos los datos sobre los poseedores del impreso anteriores a él ${ }^{39}$.

Recapitulando la información de la que disponemos, queda claro que Francisco Asenjo Barbieri (1823-1894) fue uno de los primeros poseedores del libro, pues, teniendo en cuenta las fechas que hemos venido manejando para la publicación del impreso, es probable que, antes que en las suyas, estuviera en manos de otra persona, cuya identidad actualmente se desconoce. Barbieri, conocido históricamente por su labor como musicólogo, fue una de las personalidades más influyentes dentro de la cultura española del siglo XIX, no sólo en su faceta musical, sino también en la bibliófila, la crítica y la literaria ${ }^{40}$.

Como es sabido, antes de su muerte el compositor madrileño dejó constancia de su deseo de donar toda su colección a la Biblioteca Nacional, que por esas fechas aún no había sido inaugurada. A pesar de que sus fondos fueron efectivamente entregados a la Biblioteca, el ejemplar del Arte de putear nunca llegó a formar parte del «Legado Barbieri», pues antes de su fallecimiento el libro pasó a engrosar la biblioteca de su buen amigo don Luis Carmena y Millán (1845-1903), historiador musical y autor de algunos de los tratados taurinos más importantes de la época ${ }^{41}$.

Por último, probablemente en los años que se encuentran a caballo entre el siglo XIX y el XX, don Luis Carmena y Millán le regaló el ejemplar del Arte de putear a su íntimo amigo y compañero de aficiones don José Bilbao (1868-1955), músico filarmónico, amante de la tauromaquia y, como su querido amigo, historiador musical.

Llegamos, con esto, al 23 de mayo del año 1935, fecha en la que don José Bilbao le cede la posesión de tan preciado libro a su estimado amigo don José Subirá Puig (1882-1980), que, como casi todos los anteriores, ha sido recordado históricamente como musicólogo y crítico musical, aunque obtuvo el doctorado en

${ }^{39}$ En cuanto a la posible existencia de otro ejemplar en la Biblioteca Nacional, no se ha podido encontrar por el momento referencia alguna.

${ }^{40}$ A pesar de nuestro afán por buscar las posibles fechas en las que el insigne musicólogo contó con el Álbum de Venus en su colección, no ha sido posible encontrar referencia alguna Véase, por ejemlo, H. Serís (1964), t. 1, pp. 178-191, donde se reproducen varias cartas en las que el compositor trata sobre su fondo bibliográfico, pero nada dice acerca de esta peregrina edición moratiniana.

41 Tras consultar la correspondencia conservada en la Biblioteca Nacional entre Luis Carmena y Millán y Francisco Asenjo Barbieri, L. Carmena y Millán (1878-1890), no hemos podido encontrar información alguna acerca de la posible fecha en la que el musicólogo madrileño le entregó el libro que nos ocupa a su amigo. 
Derecho en 1923. Entre sus condecoraciones más importantes está la de haber sido nombrado académico numerario de la Real Academia de Bellas Artes de San Fernando, en $1952^{42}$. A partir de este momento, la información que tenemos acerca del peregrino impreso crece considerablemente. En un principio, debemos suponer que el libro llegó a manos de don José Subirá en 1935; que el musicólogo se lo prestó a don Antonio Rodríguez-Moñino ${ }^{43}$; y que, tras su devolución, el ejemplar desaparece, pues hemos comprobado que en 1977 don José asegura que la obra ya no se encontraba en las estanterías de su biblioteca.

La historia, hasta el momento, no parece tener ningún secreto. Sin embargo, tres cartas que se adjuntaron con la donación del ejemplar a la Biblioteca Nacional nos permitirán arrojar luz nueva sobre el peregrinaje del libro en estos años. La primera, fechada el 13 de febrero de 1972, va firmada por Philip Deacon, que por esas fechas estaba preparando su tesis doctoral sobre Nicolás Fernández de Moratín. El profesor Deacon comenta que ha sabido de la existencia de la edición del Arte de putear gracias al Manual de Palau y le pide una reproducción, aunque don José, por lo que sabemos, nunca contestó al profesor inglés. De hecho, un año más tarde, en octubre de 1973, el doctor Francisco Aguilar Piñal escribe a su amigo Subirá para interceder en favor del británico, y aunque en esta ocasión sí conservamos la contestación del musicólogo, en ella únicamente se apunta: «debo manifestar a usted que no obstante mi amor a los autógrafos [...], no poseo ninguno de los dos Moratín (padre e hijo). Así puede comunicárselo usted al profesor inglés Philip De-ca-con [sic]».

Además de las dos anteriores, la carpeta contiene una carta más, firmada el 17 de enero de 1977 por el profesor Manuel Fernández Nieto, que en esos momentos estaba preparando su edición del Arte de putear. En ella, el remitente de nuevo hace referencia al Manual de Palau y le pide a Subirá que le permita ver la edición para completar su trabajo. Don José contesta a la carta, y las palabras que utiliza son exactamente las que reproduce Fernández Nieto en la nota de su edición, es decir, que hace muchísimo tiempo tuvo el poema en sus manos, «pero ignora quien [sic] lo posee suponiendo que se conserve todavía».

Todas estas afirmaciones no resultarían sospechosas y contradictorias si no fuera por una breve anotación que encontramos en el sobre que contenía la obra a la hora de su donación y que reza: «[me lo] regaló la Sra. Subirá a 21-VI-1981». En efecto, cuando el musicólogo murió, en 1980, aún mantenía el ejemplar entre sus libros, y sólo tras su fallecimiento su mujer decide legárselo a Jaime Moll Roqueta (1926-2011), que, con la breve línea transcrita arriba, nos permite resolver al fin

\footnotetext{
${ }^{42}$ Para las referencias biográficas véase el «Editorial» que le dedicó tras su muerte la revista Ritmo (1980).

${ }^{43}$ De nuevo, no hemos podido encontrar ninguna referencia cronológica para datar el momento en el que se llevó a cabo el préstamo, pues nada se dice acerca del ejemplar en la poca correspondencia conservada entre don José Subirá y don Antonio Rodríguez-Moñino, J. Subirá (1953-1957).
} 
este pequeño enigma que se escondía tras la historia del ejemplar. Jaime Moll, que comenzó su carrera académica dentro de la musicología, llegó a ser la máxima autoridad española en historia del libro antiguo ${ }^{44}$. Fue tan eminente bibliófilo el último propietario de este libro de azarosa vida, y en los fondos de su inmensa biblioteca lo mantuvo hasta su muerte.

Será unos meses después de su fallecimiento, en febrero de 2012, cuando su esposa Mercedes Dexeus Mallol, ex-directora del Departamento de Patrimonio Bibliográfico de la Biblioteca Nacional, done a la Biblioteca Nacional de España el único ejemplar conservado en todo el mundo de la primera edición impresa del Arte de putear de Moratín, poniéndolo al alcance de toda la comunidad científica ${ }^{45}$. No puede haber mejor momento para agradecer a doña Mercedes ese maravilloso gesto de generosidad, ya que sin él habría sido imposible la realización de este trabajo.

\section{El Arte de putear (c. 1815-1820) a la luz de sus variantes}

Este último punto del trabajo se propone completar el análisis ecdótico ya comenzado anteriormente por estudiosos de la talla de Isabel Colón, Gaspar Garrote o Veronica Orazi ${ }^{46}$.

Ciertamente, la minuciosa labor ecdótica de la profesora italiana resulta indispensable a la hora de hacerse una idea precisa de la tradición textual del Arte de putear, ya que la escrupulosa collatio de los testimonios $\mathrm{F}, \mathrm{C}$ y $\mathrm{M}$ le ha permitido consignar la existencia de «guasti d'archetipo, che consente di ipotizzare l'origine comune della tradizione [...] $\rangle^{47}$. Según estos datos, las tres copias del poema utilizadas para la edición, que no presentan errores demasiado significativos, serían codex descripti descendientes de un arquetipo común, hecho éste del que se deduce la existencia de una transmisión textual más cuidada y unitaria de lo que

\footnotetext{
${ }^{44}$ Para una breve semblanza biográfica, véase V. Infantes (2011).

${ }^{45}$ Puede consultarse la noticia de la donación en línea, en la web de la Biblioteca Nacional de España: <http://www.bne.es/es/AreaPrensa/noticias2012/AlbumDeVenus.html> Última visita: 09/12/2015.

${ }^{46}$ I. Colón y G. Garrote (1995), pp. 11-118 y 235-239, consignan y comentan todas las variantes de los manuscritos F y M, incluyendo los errores de copia. V. Orazi (2012), pp. 26-31, por su parte, completa la información añadiendo al cotejo de los anteriores el manuscrito $\mathrm{C}$, y termina por diferenciar claramente dos manos en la redacción de la copia: $\mathrm{F}$ y F2.

${ }^{47}$ V. Orazi (2012), p. 26. Resulta oportuno apuntar aquí que, a partir del cotejo realizado para la confección de este trabajo, se deduce que el último de los errores de arquetipo aportados por la profesora Orazi no es tal. Según su análisis, V. Orazi (2012), p. 27, los vv. 182-183 del Canto IV leerían: «hasta el quinto F \#\#\# C tercer M lustro / en perfecta sazón Ø están las mozas», por lo que se omitiría el obligado adverbio de negación no. Sin embargo, una revisión del pasaje permite comprobar que, realmente, todos los testimonios conservados leen correctamente: «en perfecta sazón no están las mozas» (IV, 183).
} 
podríamos haber pensado en un primer momento dadas las peculiares características de difusión que tienen este tipo de poemas clandestinos.

Pues bien, con la intención de completar estos estudios críticos, en los siguientes párrafos se irán desgranando los datos más relevantes que hemos podido colegir del cotejo de todas las copias de la obra de las que se tiene constancia hasta el momento: F, C, M, BNE y el pequeño fragmento del primer canto conservado en $\mathrm{U}^{48}$. Téngase en cuenta, no obstante, que el principal objeto de estudio de esta investigación es el peregrino volumen moratiniano reaparecido en 2012, por lo que el análisis de las variantes estará inevitablemente enfocado hacia este testimonio.

Antes de comenzar a analizar de manera sistemática este cotejo, resulta oportuno avanzar aquí que a lo largo de este punto no tendremos en cuenta las numerosas variantes que presenta BNE y que pueden explicarse fácilmente por ser errores propios del copista o, en este caso, del impresor. Como veremos, los cambios que sufre el poema en dicho testimonio son tan profundos que los fallos comúnmente cometidos en el acto de copia o de composición quedan relegados a un segundo plano. No obstante lo anterior, en las líneas que siguen se ofrece una breve y sintética lista de las principales erratas del impreso ${ }^{49}$ :

- $\quad$ Adiectio: lo siguieron FCM / los siguieron BNE (I, 219); dignos FCM / indignos BNEU (I, 532); ademan FCM / ademanes BNE (II, 272); Jacome de Trezo FCM / Jacome de Trenzo BNE (II, 379); enamora F / enamorar MC / enamorara BNE (IV, 411); practico FCM / practicon BNE (IV, 474).

- Detractatio: acallaran FCMU / callaran BNE (I, 65); al saberlo FCM / a saberlo BNE (I, 449); chupo FCM / cupo BNE (II, 81); del Chocante FCM / de Chocante BNE (II, 302); Maravillas FCM / Marvillas BNE (II, 310); atragantarlas FCM / atragantarla BNE (III, 21); dama FCM / dam BNE (III; 171); celebrar FCM / celebra BNE (III, 230); mas si Apolo FCM / mas Apolo BNE (IV, 8); tendiendo FCM / tendido BNE (IV, 341); corsario FCM / cosario BNE (IV, 474).

- $\quad$ Transmutatio: son aprendidas FCMU / aprendidas son BNE (I, 165); ya que FCM / que ya BNE (I, 613); se te FCM / te se BNE (II, 5); porque FCM / que por

\footnotetext{
${ }^{48}$ Ante la imposibilidad de consultar el manuscrito C, a la hora de consignar las variantes de este testimonio nos vemos obligados a basarnos en el cotejo realizado por la profesora Orazi (2012). No obstante lo anterior, hay que tener en cuenta que, como muestra en su estudio, las lecturas de $\mathrm{C}$ no divergen mucho de las de $\mathrm{F}$ y $\mathrm{M}$, por lo que no serían demasiado significativas.

${ }^{49}$ Dados los problemas que veremos más adelante en relación con la ordenación de versos en los testimonios BNE y U, especialmente en el Canto I, en todos los ejemplos que se transcriben en este punto se citará el número de verso correspondiente a los testimonios $\mathrm{F}, \mathrm{C}$ y M. Asimismo, en un intento por mostrar el texto con las mínimas modificaciones, todos los ejemplos aportados aquí se transcribirán paleográficamente, evitando así, en la medida de lo posible, las alteraciones e incluso los posibles errores editoriales.
} 
BNE (III, 347); se yo FCM / yo se BNE (III, 475); triunfos aplausos y apellidos FCM / aplausos triunfos y apellido BNE (IV, 198).

- Inmutatio: comieramos FCM / se comiera BNEU (I, 78); se esta FCMU / todo esta BNE (I, 106); invadido honor FCMU / invertido honor BNE (I, 157); nobleza FCMU / belleza BNE (I, 159); copiar FCM / espiar BNE (I, 363); honor FCM / horror BNE (I, 377); carnal FCM / con el BNE (I, 491); dos cosas FCM / tres cosas BNE (I, 605); hinchir F / henchir M / hinchar BNE (II, 37); falsa FCM / salsa BNE (II, 67); millones FCM / millares BNE (II, 122); paseo Verdegay FCM / palacio Verdegay BNE (II, 366); cotilla FCM / corpiño BNE (III, 12); voz FCM / vez BNE (III, 73); y hace FCM / yace BNE (III, 312); variedad FCM / vanidad BNE (III, 366); lujuriosas FCM / lascivas BNE (III, 491); humedecen FCM / obedecen BNE (IV, 191); muzada Barcelona FCM / murada Barcelona BNE (IV, 232); toro FCM / coso BNE (IV, 197).

La lista de errores anterior, que no pretende ser exhaustiva, muestra cierto descuido a la hora de componer el texto, algo que cuadra perfectamente con esos graves problemas en la numeración del impreso que comentamos en la descripción bibliográfica del ejemplar. A pesar de estas claras distracciones, hemos de tener en cuenta que los cambios más abundantes se deben a sustituciones léxicas, un tipo de variante que será esencial en nuestro comentario posterior y que, realmente, no puede deberse únicamente a los fallos cometidos por el editor del volumen. Ante esta situación, sólo un análisis pormenorizado del cotejo de cada uno de los cuatro cantos nos permitirá llegar a una posible solución que explique los profundos cambios que presenta el reaparecido ejemplar del poema.

El Canto I es, sin duda, la sección de la obra que demuestra más problemas textuales; de hecho, ya desde una primera lectura superficial del texto, cualquier lector advierte fácilmente que este primer canto está ordenado de manera muy distinta a como lo estaba en los testimonios conocidos por la crítica. En primer lugar, al llegar al v. 216, BNE salta hasta el v. 446 de F, C y M, cambio en el que coincide con el fragmento que conservamos del manuscrito U; posteriormente, al llegar al v. 596, BNE vuelve hacia atrás y continúa con el texto a partir del v. 217 de F, C y M; por último, una vez que BNE ha avanzado hasta el v. 409, el canto vuelve a dar un salto hacia adelante hasta el v. 597 de F, C y M, con los que coincide ya hasta el final del canto. Estas profundas modificaciones podrían tener muchas y muy diversas explicaciones, desde la simple confusión de versos hasta el arbitrario capricho del editor; sin embargo, el hecho de que el fragmento conservado del testimonio $\mathrm{U}$ coincida exactamente en el primer salto de texto con BNE despierta nuestras sospechas, pues la posibilidad de que existiera una rama alternativa a la ya conocida dentro de un hipotético stemma crece notablemente. Hemos de considerar, además, que la reorganización de los versos no es ni mucho menos aleatoria, ya que los saltos textuales pueden explicarse perfectamente por la coincidencia temática: en BNE los temas parecen agruparse de una manera más lineal que en F, C y M, donde las contradicciones se van intercalando unas con otras 
en una especie de estructura circular concéntrica que permitiría al autor incidir aún más en esa buscada ambigüedad que desarrolla a lo largo de todo el poema.

Una segunda consecuencia del intercambio de fragmentos es el alto número de versos que se omiten en este primer canto: el poema salta del v. $216 \mathrm{al} \mathrm{v.} 446 \mathrm{y}$, al regresar, avanza desde el v. 217 hasta el v. 409, lo que significa que los 36 versos que hay entre el v. 410 y el v. 445, ambos inclusive, han sido absolutamente omitidos en la edición del texto. De hecho, la supresión de versos no se queda sólo en esta treintena, puesto que tampoco se reproducen aquí los vv. 62-63, 241, 246, 251-254, 398, 458-456 y 464-465. Asimismo, algunos otros fragmentos aparecen claramente deturpados, como los vv. 44, 254 y 573, donde la edición reproduce heptasílabos en lugar de endecasílabos, como en F, C y M. El resultado de tan cuantiosas omisiones tiene una clara consecuencia en el recuento final de versos, ya que $\mathrm{F}, \mathrm{C}$ y $\mathrm{M}$ cuenta con 615 versos en el Canto I mientras que BNE suma únicamente 582 en la misma sección.

A cambio de estas irrecuperables supresiones, el poema que reproduce el ejemplar decimonónico amplía en unas pocas ocasiones el texto de Moratín, añadiendo algunos versos más a los ya conocidos. Además, las adiciones de BNE tampoco aparentan estar compuestas de forma aleatoria, pues en la mayor parte de los casos se mantiene la métrica y la rima, lo que nos hace dudar de la posible validez de dichas variantes:

\section{FCM}

[...] el que aun no entienda

la llamada del rigido apetito, no me lea a no ser que advertencias pretendiese $[\ldots]$ (I, 30-32)

\section{FCMU}

[...] quien bastara a adornar FCM / domar U de resistencia para que el otro sufra eternamente a una muger fantastica insolente; que fiada en el lazo indisoluble tiranamente usurpa el despotismo del hombre, su prudencia despreciando? (I, 53-58)

FCM

[...] y si los brutos, y abes la observaran comieramos de viernes todo el año:

\section{BNEU}

[...] el que aun no entienda

La llamada del rigido apetito,

Los castos ojos huya de mi escrito, A no ser que advertencias pretendiere (I, 30-33)

BNE

¿Por que se ha de clamar siempre prudencia Para que un pobre sufra eternamente A una muger fantástica insolente; Coqueta, lenguaráz, puta voluble Que fiada en el lazo indisoluble Mas duro á veces que el tremendo infierno Tiranamente arrebatada del gobierno Del hombre, y su virtud es despreciada? (I, 54-61)

BNE

[...] Que si los brutos y aves la observáran Se comiera de viernes... ayunáran ${ }^{50}$

\footnotetext{
${ }^{50}$ En este caso, $\mathrm{U}$ coincide con BNE, aunque no ocurre lo mismo con los otros versos que completan este fragmento.
} 
pero porque abrazar el himeneo muchos en los demas escarmentados aborrecen tenaces y templados [...] (I, 77-81)

[...] si el tuyo ya no puedes sugetallo y empinandose pierde la obediencia que no hay remedio, y de tu edad florida deja que goze, vaya ese nublado [...] (I, 608-611)
Los que van y no van al jubileo.

Hay muchos que abrazar el himeneo En el ajeno mal escarmentados, Aborrecen tenaces; y templados [...] (I, 78-83)

Si el tuyo ya no puedes sujetallo Y empinándose pierde la obediencia, Tenga tu padre ó tu rector paciencia, Que no hay remedio; y de tu edad florida Deje que goces; váyase el nublado [...] (I, 572-586)

Si estas cuatro adiciones son ya absolutamente novedosas dentro de la tradición textual del Arte de putear, aún más interesante resulta el fragmento de poema que se encuentra entre los vv. 541 y 568 - donde se habla del filósofo Diógenes-, ya que la ampliación que lleva a cabo BNE en esta parte es la más extensa de todas las del testimonio $^{51}$ :

FCMU

El Diogenes filosofo de rara penetracion asi penso prudente: mil veces la linterna reluciente arrimó a aun lado, con que de dia un hombre buscaba y no le hallo entre tanta gente y a la primer muchacha qe encontraba con franca y muy marcial filosofia en medio de una plaza la tendia, y soltando los anchos zaragüilles se halzó las respetables sopalandas, y sin gastar respuestas ni demandas con experimental filosofia si active o si pasive concurria a la generacion la hembra, quiso indagar; mas turbose de improviso, viniendole temblores y esperezos, y al darla ansioso desdentados besos las blancas barbas de babazas llenas ni aun la dejaban respirar apenas y el bellaco filosofo apretaba: toda Atenas atento lo miraba
BNE

Diójenes, filósofo de rara

Penetración, así pensó prudente, Una vez la linterna reluciente Arrimó a un lado, con la cual buscaba Un hombre que solícito no hallaba Segun los ritos de su docta escuela. Encontrándose al paso una mozuela De lindos ojos y robustas tetas

De esas que son estímulo a braguetas,

Sin reparar el paso de la jente, Con franco y reposado continente, En medio de la plaza,

La tumbó con cachaza, $\mathrm{Y}$ con gentil talante

Se lo sopló al instante

Dejando á un lado la filosofía;

Mas queriendo indagar si concurria

A la jeneracion la tal mozuela, Frenético apretábale la espuela, $\mathrm{Y}$ entre respingos mil de dulce pena Voyantes conducian la faena.

51 Téngase en cuenta, además, que si en las ampliaciones anteriores BNE coincide en algunas variantes con $\mathrm{U}$, en el fragmento que reproducimos a continuación los testimonios son absolutamente dispares. Si consideramos que ambos documentos concordaban en la alteración del orden de los versos, podemos deducir que U, muy probablemente, estaría nutriéndose para la copia de dos ramas de la tradición textual a la vez. 
y el vil Pueblo ignorante y religioso

y el Areopago se escandalizaba;

y el sabio asi amolando como estaba sin sacarlo alzó el rostro, y dijo: o Necios; no os admireis con risas y desprecios, que cosa natural es la que hago, $\mathrm{y}$ es licito lo que es naturaleza. (I, 541-568)

Viniéronle temblores y esperezos, $\mathrm{Y}$ al darla ansioso desdentados besos, Las blancas barbas de babazas llenas $\mathrm{Ni}$ aun la dejaban respirar apenas, Y el profundo filósofo apretaba:

Toda Atenas atenta le miraba, Y el vil pueblo, ignorante y relijioso, Y el Areópago se escandalizaba, Y el sabio asi jodiendo como estaba, Sin sacarlo alzó el rostro y dijo: «necios, No os admires con risas ni desprecios, Que cosa natural, es la que hago Y es lícito lo que es naturaleza; [...] (I, 310-341)

Como podemos observar, incluso en una lectura superficial, la ampliación y las sustituciones léxicas en este pequeño fragmento son muy considerables. Tanto es así que únicamente el análisis profundo de todos los cantos de BNE podrá llevarnos a una potencial solución del problema que representan estas lecturas, pues dado que la métrica y el estilo son perfectamente equivalentes, a priori no podríamos saber cuál de las dos versiones es la que más se acercaría a la intención de Moratín al escribir la obra.

Una última cuestión interesante que aporta BNE es aquella que tiene que ver con las sustituciones léxicas, muy numerosas en el transcurso de todo el testimonio. La mayor parte de estas variaciones textuales podrían considerarse lecturas equipolentes, pues, en general, las palabras suelen reemplazarse por sinónimos y los cambios no modifican sustancialmente el sentido del poema. Así ocurre, entre otros muchos ejemplos, con: aspero dinero FCM / mísero dinero BNE (I, 50); el brutal apetito FCM / el carnal apetito BNE (I, 90); fulminando del pulpito amenazas FCM / fulminando en el pulpito amenazas BNE (I, 104); se miran FCM / muchos se ven $\mathrm{BNE}$ (I, 118); pues muchos hallaras FCM / muchos encontraras BNE (I, 238); galantear FCM / cortejar BNE (I, 507)...

Más allá de estos aleatorios cambios, durante todo el Canto I encontramos continuamente un tipo de inmutatio que parece responder a un patrón concreto: las metáforas eróticas que enmascaran las referencias sexuales más evidentes son reemplazadas de forma generalizada en BNE por su sinónimo más zafio y vulgar. De esta forma, el léxico del poema editado a principios del siglo XIX se vuelve mucho más explícito y, por tanto, menos ingenioso: engendrando FCM / fornicando BNE (I, 240); putañeros FCM / jodedores BNE (I, 453); meretrices FCM / coños $\mathrm{BNE}$ (I, 468); instrumento FCM / carajo BNE (I, 479); eso otro FCM / joderse BNE (I, 538); amolando FCM / jodiendo BNE (I, 564); obrar FCM / joder BNE (I, 589). Como se verá, esta tendencia a utilizar un vocabulario más grosero se mantendrá viva a lo largo de toda la editio princeps. 
Los problemas textuales descritos para el primer canto se mantienen en buena medida en el desarrollo del Canto II, aunque esta segunda sección del poema da la sensación de ser textualmente más estable que la precedente. En efecto, las omisiones son mucho menos numerosas en esta parte, donde únicamente se suprimen los dos versos que van desde el 168 al 169. Además, como ya había ocurrido en algunos fragmentos del canto primero, BNE se permite ampliar el poema con respecto a los demás testimonios, aunque esta vez sólo hay adiciones en una ocasión:

FCM

[...] que conexion tendra con su trabajo ya la mujer que ni aun la propia quiere sin dadiva especial estar debajo.

(II, 31-33)
BNE

[...] ¿Que conecsion tendra con su trabajo?

A tal estremo la codicia trajo

Ya á la mujer, que ni aun la propia quiere

Sin dádiva especial estar debajo; [...]

(II, 31-34)

El resultado final de versos dentro del Canto II, sumando supresiones y adiciones, arroja una cifra mucho más homogénea que en el apartado anterior, pues si F, C y M tienen un total de 412 versos, BNE llega hasta los 411, perdiendo únicamente uno.

Tampoco son tan numerosas ni tan profundas en esta ocasión las sustituciones léxicas, aunque hay que señalar que la tendencia a utilizar un vocabulario más explícitamente sexual se sigue manteniendo: amolar FCM / joder BNE (II, 367); testículos FCM / cojones BNE (II, 398); ingles FCM / coños BNE (II, 405).

Más interesante para el objetivo de este trabajo es el Canto III, pues en él, de nuevo, la profusión de variantes puede ayudarnos a la hora de encontrar una potencial solución del problema crítico que supone la explicación de los múltiples cambios de BNE.

El número de versos omitidos se dispara otra vez hasta los diez: vv. 34, 43-44, $48,109-111,119-120,132,197-198$ y 278 . Sin embargo, de la misma forma que las supresiones son mucho más notables que en el canto segundo, también lo son las adiciones. Efectivamente, de forma similar a lo que ocurría en el canto primero, esta sección de la edición de BNE añade hasta cuatro versos en cuatro fragmentos diferentes del poema, que no habían aparecido en ninguno de los testimonios conservados:

FCM

[...] y la Narcisa, celebre Gitana,

y la Carreterota Catalana;

(III, 47-48)

[...] la mas diestra de todos los humanos: y la Frazca, la Ygnacia, y la Teresa, $[\ldots]$
BNE

[...] Y la Narcisa, célebre jitana,

Que tiene un coño como una manzana.

[verso omitido]

(III, 44-45)

[...] La mas diestra de todos los humanos

En tocar la puñeta con dos manos; 
(III, 127-128)

[...] y su testamentaria la Belona,

La Tribalda, la celebre Matea. [...]

(III, 131-132)

[...] en el c... candial dela Pitona,

$\mathrm{O}$ la que vive en frente de la Puerta [...]

(III, 358-359)
Y la Frasca que vive en la tahona, $[\ldots]$

(III, 119-121)

[...] Y su testamentaria la Ramona

Que tiene un papo como un real de plata:

[verso omitido]

(III, 124-125)

[...] En el coño candial de la Pitona,

De la Celina ú de la colegiala,

O la que vive enfrente de la Puerta [...]

(III, 348-350)

El total de la suma de los versos muestra una clara falta de texto en BNE, ya que únicamente llega a los 480 versos, frente a los 490 de F, C y M.

En cuanto a las sustituciones, BNE nos muestra en este tercer canto una situación muy similar a la que ya hemos estudiado en el primero, pues encontramos muchas lecciones equivalentes en las que una palabra se cambia por otra de significado similar, manteniéndose el sentido del texto intacto: porque, segun el genero de caza FCM / como según el genero de caza BNE (III, 1); en mi verso FCM / en mi canto BNE (III, 25); con Abates FCM / con frailes BNE (III, 185); la tia Estefania FCM / la vieja Estefania BNE (III, 380); las Ducas FCM / duquesas BNE (III, 384); un buen culo FCM / mejor culo BNE (III, 481)...

Como en los dos casos anteriores, también aquí los eufemismos sexuales son continuamente reemplazados por términos de un gusto mucho menos refinado: miembro FCM / nabo BNE (III, 17); pechos FCM / tetas BNE (III, 56); Venus FCM / coños BNE (III, 93); que hay en Madrid FCM / que joden en Madrid BNE (III, 99); coito FCM / jode BNE (III, 166).

A todo lo anterior hay que añadir en esta ocasión un nuevo problema textual derivado de las variaciones léxicas, ya que durante todo el canto tercero los nombres de las prostitutas y los personajes que se van desgranando en el poema cambian constantemente, o incluso llegan a omitirse por otras palabras de sentido totalmente distinto. Esta característica ya parece avanzarse en el Canto II, donde leemos «Jacome Roque» en F, C y M, pero «Tócame Roque» en BNE (II, 307). Sin ánimo de ser absolutamente exhaustivos, obsérvese la cantidad de ejemplos que se pueden aducir en relación con este tipo de variantes: la Torre, santificada FCM / Inesilla, desvirgada BNE (III, 16); magisima Nevera FCM / Mácsima, nevera BNE (III, 45); Belica FCM / Belisa BNE (III, 66); Poneta y Pona FCM / graciosa Paca BNE (III, 87); Paquita Sanguoza y la Cañota FCM / Paca la Sanguesa BNE (III, 111-112); Tecla y Liarta FCM / Luisa BNE (III, 115); Belona FCM / Ramona BNE (III, 131); Ysabel de Ceuta, y Anastasia FCM / Ysabel de Ceuta, que galana BNE (III, 164); Gertrudis FCM / Conchita Argüelles BNE (III, 167); Gertruditas FCM / Conchita BNE (III, 177); Pascual Brey FCM / Pepeillo BNE (III, 222); Romero FCM / Lechero BNE (III, 227)... 
Si obviamos algunos claros errores de composición, como Relata FCM / Beata BNE (III, 101) o Rosana FCM / Rosona BNE (III, 468), podemos observar que, nuevamente, no todos estos cambios se pueden explicar por los fallos comunes del copista o del impresor, ya que incluso parece haber cierta lógica en la mudanza de nombres: Gertrudis se mienta en dos ocasiones y en las dos es sustituido por Conchita. A la luz de estos datos, las sospechas de que exista una redacción alternativa del poema en una rama distinta de la tradición textual se acrecientan más aún de lo que habríamos podido pensar en primera instancia.

El cuarto y último canto es, sin duda, el más defectuoso de todos los que reproduce $\mathrm{BNE}$, puesto que los problemas críticos que venimos describiendo durante todo el análisis del testimonio se acrecientan visiblemente en esta sección del poema. El número de omisiones es casi tan alto como el del Canto I, pues la suma total de ausencias asciende hasta los 34 versos y las lagunas textuales que presenta BNE llegan a omitir tiradas de diez versos o más: vv. 37-48, 75-77, 204205, 215-219, 318-319, 447-457. Además, si en el canto que abre el poema las adiciones eran también muy numerosas, algo que permitía maquillar sus graves carencias, en el Canto IV este tipo de ampliaciones se desarrollan solamente en una ocasión, donde se añade un único y solitario verso:

FCM

pues son la primera FC / primer M vez todas hermosas,

pero aunque tienen almas indomables, jubentud Española te aconsejo [...]

(IV, 320-323)
BNE

La vez primera todas son hermosas

Y mas si están haciendo aquellas cosas:

Pero aunque tienen almas indomables, Juventud española, te aconsejo [...]

(IV, 297-300)

Así las cosas, la suma de versos final arroja un resultado incuestionable: los 445 versos de los que consta BNE muestran un testimonio visiblemente deturpado con respecto a los 475 de $\mathrm{F}, \mathrm{C}$ y $\mathrm{M}$.

En cuanto a los cambios léxicos, en este canto siguen siendo abundantes los reemplazamientos de palabras por sinonimia, aunque aquí se acrecientan las malas lecturas, que no eran tan comunes en las secciones precedentes: Lavenana FCM / Severiana BNE (IV, 120); de la bulva se mueben y humedecen FCM / de la vulva se mueven y obedecen BNE (IV, 191); Otomano FCM / Otomaco BNE (IV, 348); Corsario FCM / cosario BNE (IV, 474); practico FCM / practicon BNE (IV, 475). Por último parece que la tendencia a utilizar un vocabulario más obsceno de BNE continúa, efectivamente, hasta el final de la edición: amueles FCM / jodas BNE (IV, 17).

Llegados a este punto, podemos ya concluir que el testimonio BNE muestra una serie de cambios muy claros que se mantienen en todo el poema: en primer lugar, todos los cantos se encuentran deturpados debido a las continuas omisiones; en 
segundo, a pesar de estas pérdidas, también se aprecia una clara tendencia a innovar y ampliar el poema con versos desconocidos hasta ahora por la crítica; por último, las sustituciones léxicas son claras y visibles a lo largo de toda la obra, llamando especialmente la atención las modificaciones del vocabulario más explícitamente sexual y las alteraciones en los nombres propios que jalonan el poema. A todo lo anterior habría que añadir, además, esa fuerte alteración del orden que encontramos en el primer canto, sin duda el más interesante críticamente, que nos muestra una absoluta reorganización del texto, hecha muy probablemente a posteriori con el fin de conseguir una estructura temática más lógica y lineal.

Pues bien, si nos paramos a pensar en la cantidad de variantes que hemos ido desgranando en los párrafos anteriores, la idea de que tal cantidad de cambios se deban únicamente al poco tino del editor o del componedor del poema $-\mathrm{O}$ de ambos - parece estar muy alejada de la realidad crítica del texto. En efecto, mucho más plausible resultaría la teoría de que un desconocido autor decidiera en un momento determinado incluir una serie de innovaciones en el poema tiempo después de que éste ya hubiera sido absolutamente concluido por parte de Moratín. Este inoportuno autor anónimo, que dadas las características de las obras clandestinas debió de sentirse con pleno derecho a incluir sus propias modificaciones en el Arte de putear, provocó con su acción un desastre literario, pues a partir de ese momento el lector que se acercara al poema difícilmente podría diferenciar cuáles eran las variantes originales y cuáles las lecturas posteriores. Además, al incluirse el texto dentro de lo que se conoce como la tradición abierta, las posibilidades de que algún otro aficionado a la literatura erótica contribuyera a aumentar estas innovaciones se multiplican peligrosamente.

Ante esta situación, cualquier persona que se decidiera a hacer una copia del poema y que dispusiera en ese momento de las dos versiones seguramente se decantaría por utilizar ambas, guiándose de su olfato poético a la hora de elegir las variantes y contaminando, así, el texto original. Este hecho explicaría perfectamente que el texto reproducido en $U$ conserve en varias ocasiones lecturas equivalentes a las de BNE, como el orden de los versos del Canto I, pero difiera de la edición en algunas otras, como en el largo pasaje que trata del filósofo Diógenes transcrito arriba. Extrapolando esta forma de actuar al terreno de la imprenta, no sería descabellado pensar que el editor encargado de la edición de este ejemplar del Arte manejara varias copias manuscritas a la vez a la hora de fijar el texto del poema, eligiendo en cada ocasión la variante que en ese momento le pareciera más satisfactoria.

Más allá de la clara contaminación que muestra el texto, debemos admitir que la enorme cantidad de lagunas textuales que encontramos en BNE no pueden explicarse nuevamente por la falta de pericia y el descuido del editor o del componedor de la imprenta. Teniendo en cuenta que una edición impresa reproduce inexorablemente el texto de una o, como hemos sugerido, varias copias manuscritas, parece indubitable que la mayoría de estas omisiones debían estar ya presentes en 
las copias que manejó el editor a la hora de preparar la tirada del libro. En efecto, a principios del siglo XIX las copias del Arte de putear debían de ser ya bastante defectuosas, pues en uno de los diálogos que se reproduce en Los Vicios de Madrid los personajes comentan: «Este es el sovervio Arte de putear de Nicolás Fernández de Moratín, tio [sic] de D. Leandro; es larguisimo, pues tiene tres cantos. En él pone todas las putas que habia en Madrid en su tiempo» ${ }^{52}$. Para estos editores, de esta cita se debe deducir que el receptor de tan preciado poema leyó «seguramente los tres últimos [cantos], a juzgar por el breve resumen que ofrece de su contenido» ${ }^{53}$; sin embargo, teniendo en cuenta que en el examen de BNE realizado arriba es el Canto IV el más deturpado de todos, lo más probable es que fuera esta última sección la que primero empezara a corromperse. De hecho, fuera de estas evidentes pruebas documentales, no debemos olvidar que, a lo largo de la historia, la situación crítica más común es que sea precisamente la parte final de un poema la primera que comienza a perderse en la sucesión de copias.

Así las cosas, no podemos sino concluir que BNE muestra a lo largo de sus cuatro cantos un texto absolutamente contaminado y corrupto que se aleja notablemente de la intención primigenia de Moratín. Este hecho, unido a los cuantiosos errores y las graves lagunas de las que adolece dicho testimonio, provocaría que la mayor parte de las variantes que reproduce esta primera estampación del poema tengan que ser desechadas a la hora de fijar un texto fiable, aunque evidentemente deberían ser reflejadas en el aparato crítico de una hipotética edición. Excepcionalmente, para evitar en la medida de lo posible la emmendatio ope ingenii, las lecturas de BNE podrían aprovecharse $-\mathrm{y}$ con mucha cautela - en aquellos fragmentos en los que otros testimonios muestren algún error insalvable, siempre que consideremos que ésta no se aparta peligrosamente de la lección original. No obstante lo anterior, hay que tener en cuenta que este tipo de enmiendas deben hacerse siempre tras un análisis mucho más profundo y sistemático del que hemos podido realizar en los párrafos precedentes y que excedería los límites de este trabajo.

Ahora bien, si es cierto que el ejemplar del poema que nos ocupa no debe ser utilizado críticamente como texto base a la hora de afrontar una edición crítica del poema, no lo es menos que su estudio nos ha permitido conocer más profundamente los oscuros vericuetos de la tradición textual del Arte de putear, que nos había parecido en un primer momento mucho más unitaria. Efectivamente, el hecho de que los dos testimonios analizados aquí por primera vez, $\mathrm{U}$ y BNE, muestren una serie de modificaciones realizadas muy probablemente por otro(s) autor(es) aficionado(s) al género, nos lleva a pensar que la difusión del poema moratiniano en

\footnotetext{
${ }^{52}$ Apud I. Colón y G. Garrote (19959, p. 16.

${ }^{53}$ I. Colón y G. Garrote (1995), p. 17.
} 
los años inmediatamente posteriores a su creación debió de ser mucho más amplia de lo que se podría deducir en un tímido acercamiento crítico inicial.

Asimismo, aparte de esta clara contaminación del poema, ya hemos comentado anteriormente que BNE reproduce un texto notablemente deturpado con respecto a los demás testimonios conservados, problema que permite corroborar esa amplia tradición textual de la que venimos hablando, pues qué duda cabe de que para llegar a esta preocupante situación el número de copias, errores y supresiones acumulados debe ser marcadamente más alto de lo que la crítica había podido argumentar hasta el momento. Todo ello, obviamente, sin olvidar que el poema no pudo llegar a cotas de difusión tan altas como una obra que entrara plenamente dentro del canon oficial de la época.

A la vista de estos datos, únicamente nos queda desear que el caprichoso destino vuelva a dar un vuelco a la situación del poema y nos permita encontrar algún testimonio más que, dormitando en las estanterías de cualquier biblioteca o librería, estará esperando la llegada de algún afortunado curioso que acierte con su signatura para devolverlo, de nuevo, a la luz del mundo. Sólo después de analizar críticamente alguno de esos perdidos papeles, cuya lectura nos ha sido, hasta el momento, negada por las vicisitudes de la historia, podremos completar el stemma y confirmar o desmentir la hipótesis sobre la tradición textual de la obra que nos hemos aventurado a proponer en los párrafos que cierran esta investigación.

\section{Obras citadas}

\section{Obras de referencia}

BOUCHER, François: Historia del traje en occidente desde la antigüedad hasta nuestros días, trad. de A. de P. Kulhman Thomann, Barcelona, Montaner y Simón S. A., 1967, pp. 360-374.

CARMENA y Millán, Luis: Cartas, tarjetas de visita y recibos de Luis Carmena a Francisco A. Barbieri, 1878-1890, Biblioteca Nacional de España, Sala Cervantes, MSS/14006/2/36.

Gayoso CARREIRA, Gonzalo: Historia del papel en España, t. 1, Lugo, Diputación Provincial D. L., 1994, pp. 80-84.

GILI, John L.: The Foulsché-Delbosc Library. Part IV. Spanish Manuscripts, Catalogue XLII, Oxford, The Dolphin Book Co. Ltd., 1963, p. 39.

Heredia, M. Ricardo: Catalogue de la bibliotèque de M. Ricardo Heredia, Comte de Benahavis, t. 2, París, É. Paul, L. Huard et Guillemin, 1891, pp. 75-76.

INFANTES, Víctor: «Jaime Moll Roqueta, callado y generoso sabio del libro antiguo», El País, 26 de octubre de 2011.

[INQUISICIÓN]: Edicto manuscrito de la Ynquisición de Corte, (20 de junio), 1777, Archivo Histórico Nacional, Inquisición, Legajo 4.428, Expediente $\mathrm{n}^{\circ} 30$, ff. $[3 \mathrm{v}-4 \mathrm{v}]$. 
[INQUISICIÓN]: Índice último de los libros prohibidos y mandados expurgar: para todos los reynos y señorios del catolico rey de las Españas, el señor Don Carlos IV, Madrid, Antonio de Sancha, 1790, p. 16a.

IRIARTE, Tomás de: «Vexamen satírico, compuesto por un caballero de la corte contra Moratín. Año de 1799», en Iriarte y su época, ed. Emilio Cotarelo y Mori, La Laguna (Sta. Cruz de Tenerife), Artemisa, 2006, pp. 511-514.

PALAU Y DUlCET, Antonio: Manual del librero hispanoamericano, $2^{\mathrm{a}}$ edic., t.v, EF, Barcelona, Librería Palau, 1951, p. 334.

[RITMO]: «La biblioteca de don José Subirá», Ritmo, núm. 499, marzo de 1980, p. 5. RODRÍGUEZ-MOÑINO, Antonio: «El licenciado Tamariz (Poeta del siglo XVI)», en Relieves de erudición (del Amadís a Goya). Estudios literarios y bibliográficos, Madrid, Castalia, 1959, pp. 79-125.

SALVÁ, Vicente: Catálogo de la Biblioteca Salvá, t. 1, Valencia, Imprenta de Ferrer de Orga, 1872, p. 148.

SERÍs, Homero: Nuevo ensayo de una biblioteca española de libros raros y curiosos, t. 1, fasc. 1, New York, Hispanic Society of America, 1964, pp. 178-191.

SuBIRÁ, José: Cartas a don Antonio Rodríguez-Moñino, 1953-1957, Real Academia Española, Legado de don Antonio Rodríguez-Moñino y doña María Brey, M-RAE ARM III-1-1015.

[VV.AA.]: Cartas adjuntas a la donación del ejemplar del Álbum de Venus, seguido del Arte de putear de Moratín, 1973-1977, Biblioteca Nacional de España, Sala Cervantes, R/41561. 


\section{Estudios generales}

«ADVERTENCIA» (1898) = INFANTES, Víctor: Arte de las putas debido al cálamo de Nicolás Fernández de Moratín entre los Árcades de Roma Flumisbo Thermodonciaco. A la luz de nuevo en su centenario con una Iniciatio ad usum lupanaris poeticae de Un Árcade futrosófico (18981998), Barcelona, Delstres, 1998, pp. 5-11.

AguiLar PIÑAL, Francisco y DEACON, Philip: «Bibliografía de Nicolás Fernández de Moratín», Revista de Literatura, vol. 42 (84), 1980, pp. 274-300.

CEREzo, José Antonio: Literatura erótica en España: Repertorio de obras 15191936, Madrid, Ollero y Ramos D. L., 2001.

COLÓN, Isabel y GARROTE, Gaspar: «Introducción», en Arte de putear, Archidona (Málaga), Ediciones Aljibe (Erótica Hispánica), 1995, pp. 7-124.

DEACON, Philip: «Nicolás Fernández de Moratín: tradición e innovación», Revista de Literatura, vol. 42 (84), 1980, pp. 99-120.

«E1 libro erótico en la España dieciochesca», en La memoria de los libros. Estudios sobre la historia del escrito y de la lectura en Europa y América, dirs. Pedro María Cátedra y María Luisa López-Vidriero, t. 1, Salamanca, Instituto de Historia del Libro y de la Lectura, 2004, pp. 825-837.

—-: «El espacio clandestino del erotismo literario en la España dieciochesca», en Redes y espacios de opinión pública. De la Ilustración al Romanticismo. Cádiz, América y Europa ante la Modernidad, 1750-1850, ed. Marieta Cantos Casenave, Cádiz, Universidad de Cádiz, 2006, pp. 219-230.

FERNÁNDEZ NIETO, Manuel: «Introducción», en Arte de las putas, Madrid, Siro (Biblioteca Clásica de autores festivos), 1977, pp. 13-69.

: «Entre popularismo y erudición: la poesía erótica de Moratín», Revista de Literatura, vol. 42 (84), 1980, pp. 37-52.

GIES, David Thatcher: Nicolás Fernández de Moratín, Boston, Twayne Publishers, 1979.

—_: «"El cantor de las doncellas” y las rameras madrileñas: Nicolás Fernández de Moratín en El arte de las putas», en Actas del VI Congreso de la Asociación Internacional de Hispanistas, eds. A. M. Gordon y E. Rugg, Toronto, University, 1980, pp. 320-323.

GUEREÑA, Jean Louis: Un infierno español. Un ensayo de bibliografia de publicaciones eróticas españolas clandestinas (1812-1939), Madrid, LIBRIS (Asociación de Libreros de Viejo), 2011.

Helman, Edith F.: «D. Nicolás Fernández de Moratín y Goya sobre "Ars Amatoria"», en Jovellanos y Goya, Madrid, Taurus, 1970, pp. 218-236.

INFANTES, Víctor: «Iniciatio ad usum lupanaris poeticae», en Arte de las putas debido al cálamo de Nicolás Fernández de Moratín entre los Árcades de Roma Flumisbo Thermodonciaco. A la luz de nuevo en su centenario con una 
Iniciatio ad usum lupanaris poeticae de Un Árcade futrosófico (1898-1998), Barcelona, Delstres, 1998, pp. V-X.

MENÉNDEZ Y PELAYO, Marcelino: Historia de los heterodoxos españoles, t. V, Madrid, CSIC, 1963, especialmente las pp. 272-350.

ORAZI, Veronica: «Introduzione», en Arte de las putas. Introduzione, edizione critica, traduzione e note, Alessandria, Edizioni dell'Orso, 2012, pp. 1-31.

Palacios Fernández, Emilio: «La poesía amorosa de Nicolás Fernández de Moratín», Revista de Literatura, vol. 42 (84), 1980, pp. 19-35.

— : «Panorama de la literatura erótica del siglo XVIII», en Venus venerada II: Tradiciones eróticas de la literatura española, eds. J. Ignacio Díez Martínez y Adrienne L. Martín, Madrid, Universidad Complutense, 2006, pp. 191-239.

PIQUERO, Álvaro: Álbum de Venus, seguido del Arte de putear de Moratín, Madrid, Visor, 2014.

RUIZ PÉREZ, Pedro: «Nicolás Fernández de Moratín, entre la Academia y el burdel», en Los territorios literarios de la historia del placer, eds. José Antonio Cerezo, Daniel Eisenberg y Víctor Infantes, Madrid, Huerga y Fierro, 1996, pp. 175-185.

ZAVALA, Iris M.: «Inquisición, pornografía y normas literarias del siglo XVIII», Anales de Literatura Española, núm. 2, 1983, pp. 509-529. 